\title{
THE IMPACTS OF DIGITAL MARKETING ON ONLINE SHOPPING BEHAVIOR THROUGH ONLINE SHOPPING APPLICATION IN THAI NGUYEN CITY
}

\section{Chinda Somfongbouthtakhan}

$T N U$ - International School

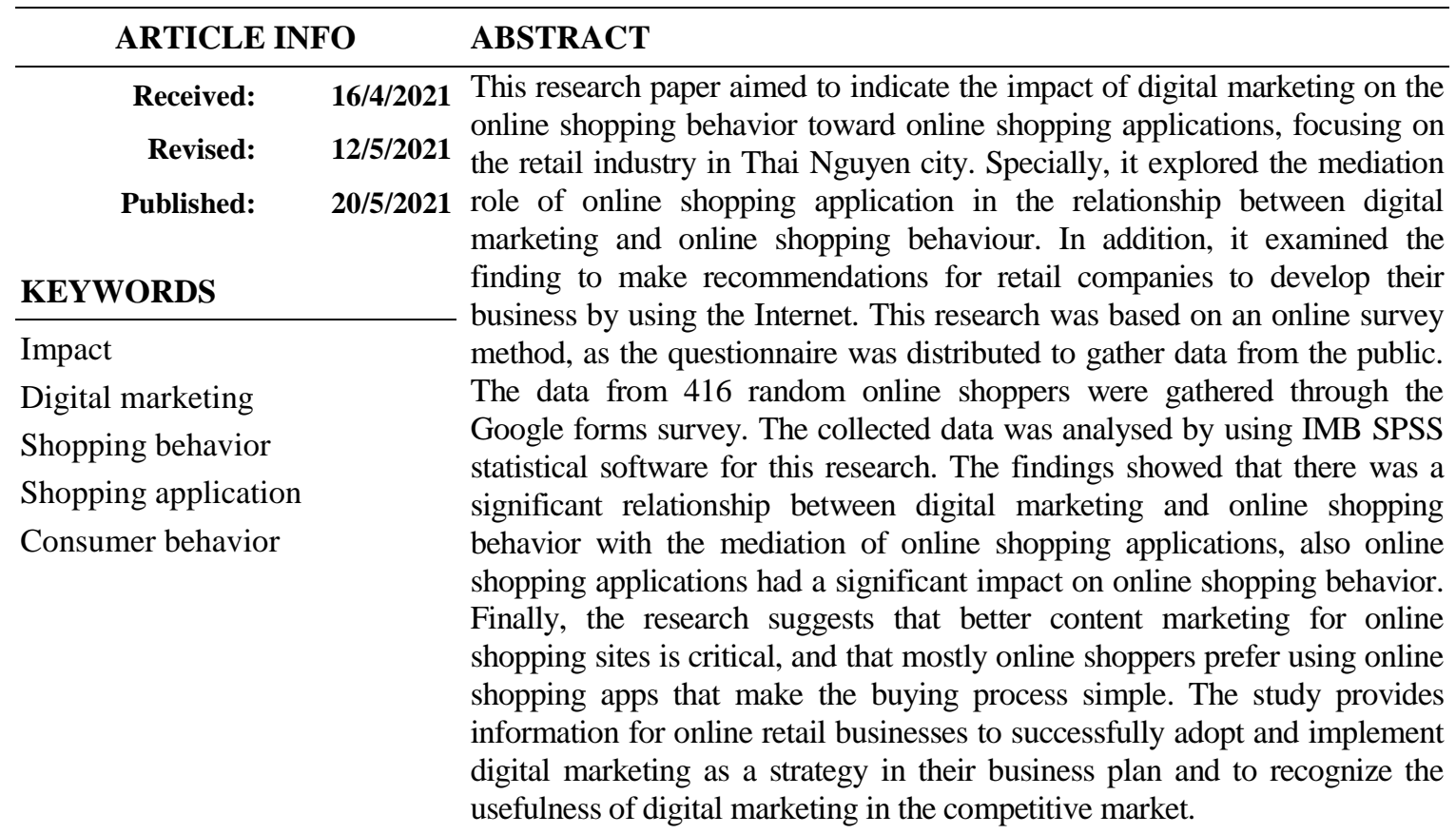

\section{ẢNH HƯởNG CỦA TIẾP THỊ SỐ ĐẾN HÀNH VI MUA HÀNG TRỰC TUYẾN THÔNG QUA CÁC ÚNG DỤNG MUA SĂM TẠI THÀNH PHỐ THẢI NGUYÊN}

Chinda Somfongbouthtakhan

Khoa Quốc tế - ĐH Thái Nguyên

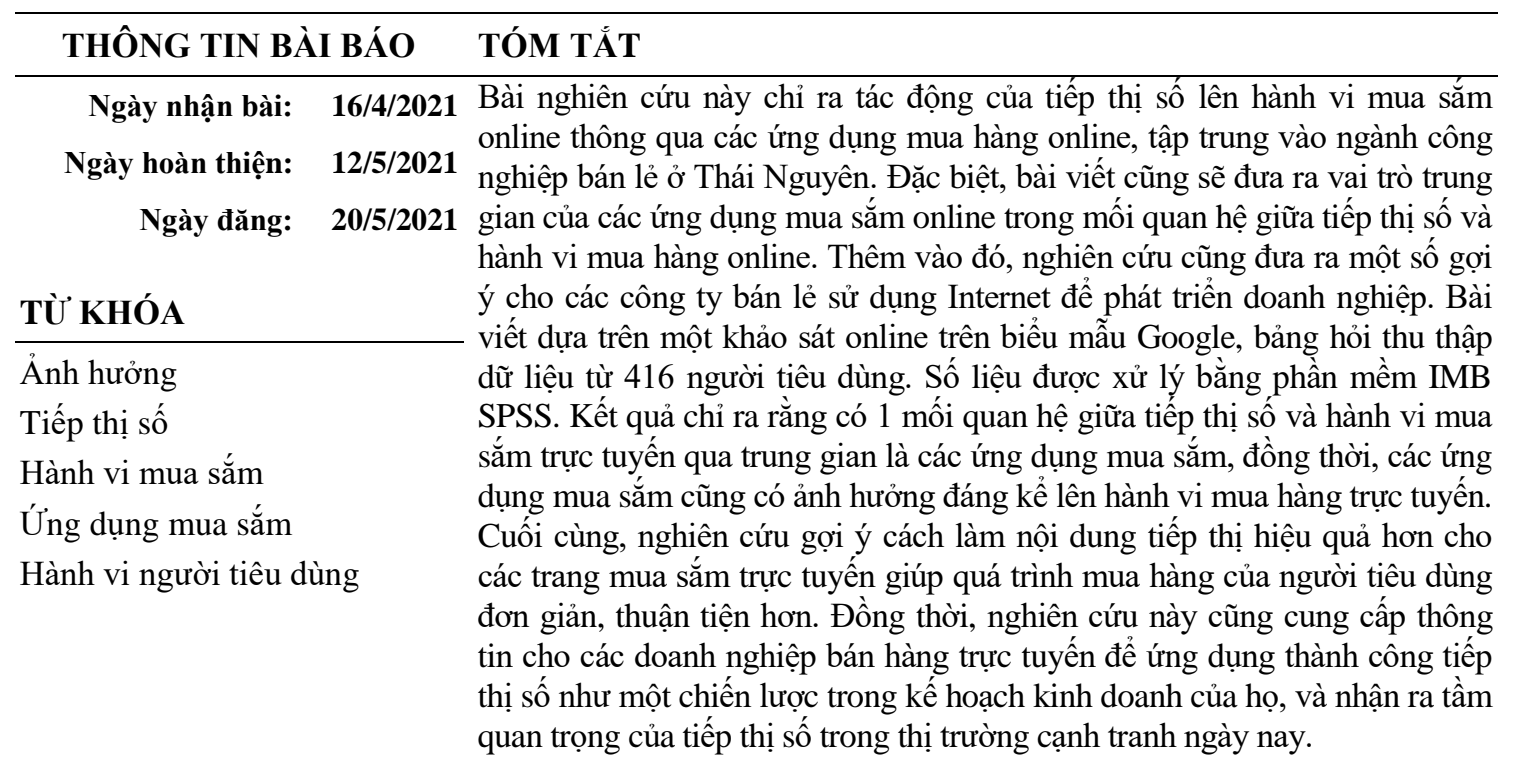

DOI: https://doi.org/10.34238/tnu-jst.4379

Email:annykm6@gmail.com 


\section{Introduction}

Due to the widespread use of the Internet, digital marketing within the society has transformed the way marketers communicate with today's consumers and digital marketing has also emerged as a brand-new marketing tool. Among the various variables investigated in the literature, previous experiments widely identify digital marketing as playing a main role in impacting online consumer behavior. Shoppers' attitudes towards the brands can be successively influenced by attitudes towards social media. The research by Abou-Elgheit [1] pointed up that understanding the changes of purchaser behavior from a wider context is significantly important. Chaffey (cited in [2]) defined digital marketing due to the employment of electrical tools to assist marketing activities so as to enhance customer knowledge by matching their needs.

The study of Gaber et al. [3] investigating consumer experiences using Instagram advertising conclude that attitudes are influenced by consumer perception of content usefulness, entertainment, credibility and lack of irritation from the Instagram advertisement itself. Kotler and Armstrong [4] determined digital marketing as a sort of marketing tool that purposes to connect buyers and sellers automatedly using multimedia technologies like emails, websites, internet forums and newsgroups, interactive television, mobile networks etc. Hence, many companies have realized the importance of digital marketing within the developed world. In order to achieve success for business, Parsons, Zeisser, Waitman [5] said that they are going to need to merge online with traditional methods for meeting the needs of consumers more precisely. Presentation of latest high technologies has generated new business opportunities for marketers to manage their websites and achieve their business objectives [6]. Online advertising could be a powerful marketing vehicle for building brands and increasing traffic for companies to realize success [7].

Besides, Kotler et al. [8], Armstrong and Kotler [9] suggested that the fast development in the social media application has benefited the overwhelming majority in the marketing practices. Additionally, Fan and Gordon [10] stated that with the analysis of social media, organizations can benefit from competitive advantages by assessing the competitor's strategies, supplier's performance and consumer behavior. Remarkably, Shukla and Nigam [11] claimed that mobile channels became the norm and are now embedded within consumers' daily lives via the utilization of mobile tools, shopping apps, based on location services and E-wallets all impacting the buyer experience. Thus, Hossain et al [12], [13] concluded that the growth of shopping channels has also influenced consumer behavior and creating a more diffused consumer shopping experience.

However, previous research of Adrita et al. [14] recommended that online retailers should give a lot of importance to price and after sale services factor. This pushed Achal and Kapil [15] to investigate the factor analysis on young online shoppers including internet facility, website security, ease of online purchase and on-time delivery influenced online buying behavior. Moreover, the finding of Sajjad et al. [16] showed that convenience, price, security, time, confidence, discounts and after sale service were the main factors that impacted on online shopping behavior, and sharing personal information was the key issue in online shopping. Thus, with the nonstop development of digital technology and internet marketing, it is an enormous challenge to keep track of those developments and to use them advantageously. Also, in the lack of published studies in that area, research is necessary to understand relevant issues lagging the online shopping behavior in Thai Nguyen city, Vietnam. That is the main reason why I was interested and sensed a demand to work on this in the study. I am sure that this research would assist business organizations in the city to develop appropriate digital marketing strategies accordingly to enhance the online shopping application. Therefore, this study proposes to investigate the impact of digital marketing on online shopping behavior toward online shopping applications with a specific focus on the retailer's industry in Thai Nguyen city, Vietnam. 
In addition, this study aims to answer two main research questions including:

- What is the role of online shopping applications in the relationship between digital marketing and online shopping behavior?

-What are implications for retail companies to develop their business using the internet?

The main intention of the present study is to explore the mediation role of online shopping application in the relationship between digital marketing and online shopping behavior. This research also supposes to provide recommendations for retail companies to develop their business using the internet.

\section{Methodology}

According to the related literature review that was used as foundation to answer research questions, the research model for this study is illustrated in Figure 1.

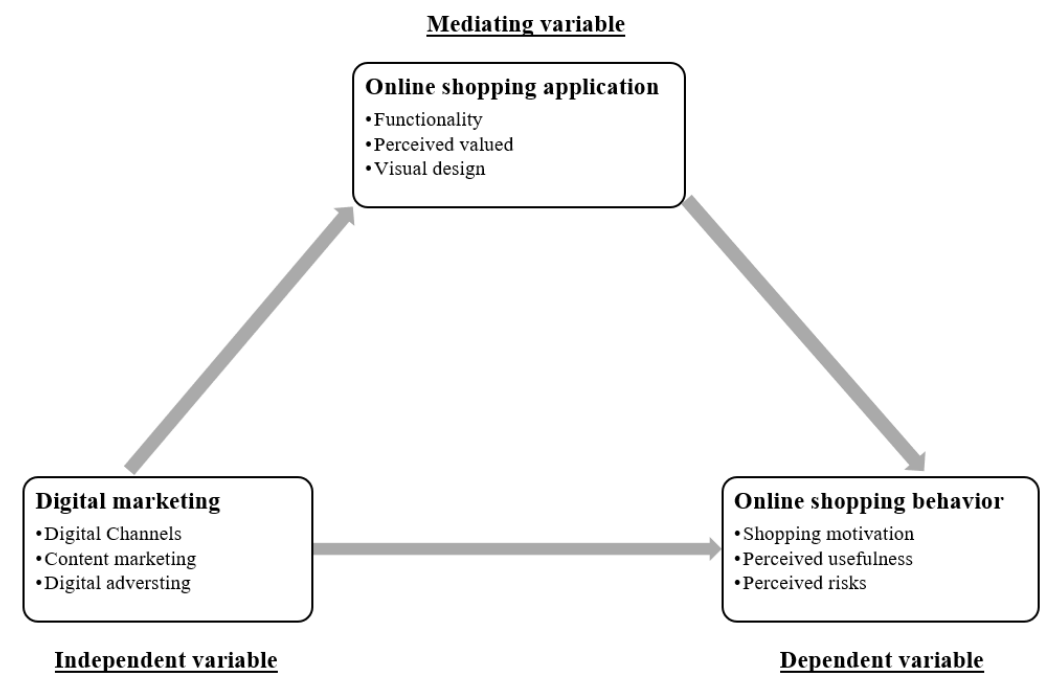

Figure 1. Conceptual framework

$H_{I}$ : Digital marketing has significant impacts on online shopping applications.

$\mathrm{H}_{2}$ : Online shopping application has significant impacts on online shopping behavior.

$\mathrm{H}_{3}$ : Digital marketing has significant impacts on online shopping behavior.

The study employed an explanatory research that the design involved formulating the hypothesis and collecting the information on this basis that leads to achievement of the objectives of the research. A survey was conducted among all online shoppers in Thai Nguyen city, Vietnam and the respondents were randomly selected. Based on Slovin's formula (1960), the total sample size of the research was 416 responses (289 females and 127 males). This sample size was determined to be relatively large and guaranteed a better reliability for the research. The primary data collection techniques were online survey research. The online questionnaire was distributed through Google Forms to gather the data and applied on a representative sample of respondents. The questionnaire generated in both English and Vietnamese versions consisted of 28 questions that included multiple-choice and 15 questions that were measured on a 5-point Likert scale questions scale. To analyze the data, the quantitative approach was used and involved using statistical tools to evaluate the collected facts and data. The exploratory factor analysis (EFA) was used to comply with factor loading and item-total correlation, also the reliability of each construct was investigated. In addition, data analysis, frequency, descriptive analysis, regression analysis, and analysis of variance ANOVA, these tests were conducted by using SPSS to determine the impact of digital marketing on online shopping behavior. 


\section{Result and discussion}

\subsection{Demographic analysis}

The study was carried out with the principal aims of conducting the impacts of digital marketing on online shopping behavior toward online shopping applications, that focused on the retail industry. As a part of the sample study, demographic information from 416 respondents was collected using Google Forms and the data is illustrated in table 1.

Table 1. Demographic analysis

\begin{tabular}{|c|c|c|c|}
\hline Variables & Characteristics & Frequencies & Percentage \\
\hline \multirow{3}{*}{ Gender } & Male & 127 & 30.5 \\
\hline & Female & 289 & 69.5 \\
\hline & Total & 416 & 100.0 \\
\hline \multirow{7}{*}{ Age } & Under 18 years old & 11 & 2.6 \\
\hline & $18-24$ years old & 328 & 78.8 \\
\hline & $25-30$ years old & 27 & 6.5 \\
\hline & $31-40$ years old & 22 & 5.3 \\
\hline & $41-50$ years old & 27 & 6.5 \\
\hline & Over 51 years old & 1 & 0.2 \\
\hline & Total & 416 & 100.0 \\
\hline \multirow{4}{*}{ Occupation } & Student & 313 & 75.2 \\
\hline & Officer & 91 & 21.9 \\
\hline & Business owner & 12 & 2.9 \\
\hline & Total & 416 & 100.0 \\
\hline \multirow{4}{*}{ Education Level } & Secondary & 37 & 8.9 \\
\hline & Bachelor degree & 343 & 82.5 \\
\hline & Master degree & 36 & 8.7 \\
\hline & Total & 416 & 100.0 \\
\hline \multirow{5}{*}{$\begin{array}{l}\text { Monthly Income } \\
\text { (VND) }\end{array}$} & Less than 5,000,000 & 293 & 70.4 \\
\hline & $5,000,000-15,000,000$ & 79 & 19.0 \\
\hline & $15,000,000-30,000,000$ & 20 & 4.8 \\
\hline & More than $30,000,000$ & 24 & 5.8 \\
\hline & Total & 416 & 100.0 \\
\hline \multirow{7}{*}{$\begin{array}{l}\text { Frequency of online } \\
\text { shopping }\end{array}$} & Everyday & 31 & 7.5 \\
\hline & $2-3$ times a week & 52 & 12.5 \\
\hline & Once a week & 64 & 15.4 \\
\hline & Few times in a month & 220 & 52.9 \\
\hline & Rarely & 45 & 10.8 \\
\hline & Never & 4 & 1.0 \\
\hline & Total & 416 & 100.0 \\
\hline
\end{tabular}

As seen in table 1, most participants were young people from two groups of age, from 18-24 years by $78.8 \%$ and from $25-30$ years by $6.5 \%$. The majority of respondents were female $(69.5 \%)$ while other respondents were male (30.5\%). $75.2 \%$ of participants are students, while $21.9 \%$ are officers and only $2.9 \%$ are business owners. This can conclude that young people spent more time on online shopping than older ones, especially women. As, most of participants were students, so 70.4\% accounts for their monthly income was less than 5,000,000 VND, and only $5.8 \%$ respondents had monthly income of more than 30,000,000 VND. Additionally, over half of the respondents shopped online a few times in a month, while only $7.5 \%$ did an online shopping every day. 


\subsection{Exploratory factor analysis EFA}

Regarding the statistical procedures, the author conducted an exploratory factor analysis EFA categories groups of difference criteria, in which similar criteria are in the same group. According to the EFA analysis for the rotated component matrix of three variables determined that each set of items does not have the inter-correlation values greater than 0.50 , only a few items, so we decided to exclude the rotated component matrix table in the study. As the result showed that all five items of online shopping application were deleted and only two items of digital marketing, and three items of online shopping behavior are greater than 0.5 , which does not indicate the individuality of items for the convergent validity. Thus, the researcher cannot take all of the items and variables for the undertaken study, also we are not able to continue to conduct the CFA, so we stopped only EFA.

\subsection{Scale reliability}

After doing EFA, some items that did not perform well were deleted (Table 2). However, the scale employed in the study has slightly high reliability. The outcomes showed that the Cronbach $\alpha$ coefficient for all the variables were within the range of 0.686 to 0.743 which are accepted. As suggested by Jonathan Wilson [17], Cronbach's alpha should be 0.60 or higher for a set of objects to be measured in a scale. Specifically, the aggregate Cronbach $\alpha$ coefficient of all questions was 0.812 which is accepted. Thus, this survey data results are reliable.

Table 2. Scale reliability

\begin{tabular}{|c|c|c|c|c|c|}
\hline \multirow[t]{2}{*}{ Construct } & \multicolumn{2}{|c|}{ Before Purification } & \multicolumn{2}{|c|}{ After Purification } & \multirow{2}{*}{$\begin{array}{c}\text { Aggregate } \\
\text { Cronbach } \alpha \\
\text { coefficient }\end{array}$} \\
\hline & $\begin{array}{l}\text { Number of } \\
\text { items used }\end{array}$ & $\begin{array}{c}\text { Cronbach } \\
\alpha \\
\end{array}$ & $\begin{array}{l}\text { Number of } \\
\text { items used }\end{array}$ & $\begin{array}{c}\text { Cronbach } \\
\alpha \\
\end{array}$ & \\
\hline Digital marketing & 5 & 0.631 & 3 & 0.709 & \multirow{3}{*}{0.812} \\
\hline $\begin{array}{l}\text { Online shopping } \\
\text { application }\end{array}$ & 5 & 0.712 & 4 & 0.743 & \\
\hline $\begin{array}{l}\text { Online shopping } \\
\text { behavior }\end{array}$ & 5 & 0.609 & 4 & 0.686 & \\
\hline
\end{tabular}

\subsection{Hypothesis testing}

The regression analysis was used to test the proposed hypothesis relationship among the variables. The results presenting digital marketing and online shopping applications to online shopping behavior are supported. The mediating role of online shopping applications had a high significant effect on online shopping behavior, providing support for $\mathrm{H} 2$. The finding on the table indicated that online shopping applications had the highest influence with $\beta=0.534$, which is a greater effect on online shopping behavior than digital marketing $(\beta=0.402)$. In addition, digital marketing also had a significant influence on online shopping applications with $\beta=0.515$.

Table 3. Summary of Hypothesis testing results

\begin{tabular}{|c|c|c|c|c|c|c|c|}
\hline Hypothesis & Regression Paths & $\begin{array}{c}R \\
\text { Square }\end{array}$ & Beta ( $\beta$ ) & SE & t-statistic & Sig & Results \\
\hline $\mathrm{H}_{1}$ & $\mathrm{DM}^{*} \rightarrow \mathrm{OSA}$ & 0.265 & 0.515 & 0.043 & 12.288 & 0.000 & Supported \\
\hline $\mathrm{H}_{2}$ & $\mathrm{OSA}^{*} \rightarrow \mathrm{OSB}$ & 0.286 & 0.5 & 0.035 & 12.862 & 0.000 & Supported \\
\hline $\mathrm{H}_{3}$ & $\mathrm{DM}^{*} \rightarrow \mathrm{OSB}$ & 0.162 & 0.402 & 0.039 & 8.941 & 0.000 & Supported \\
\hline
\end{tabular}

\subsection{Results}

In the online shopping data, digital marketing results illustrated that content marketing, digital advertisement and digital channels had influences on online shopping behavior. Additionally, the respondents preferred using the online shopping application that easily makes a purchasing process. Most online shoppers agreed that visual design and well-organized of the online 
applications or websites are important. Thus, the author can conclude that digital marketing and online shopping application had a significant impact on online shopping behavior. In addition, it can be seen that customers commonly purchased online products in domestic, while only a few preferred to buy from other countries.

The study shows that $52.9 \%$ of the respondents shopped on the Internet few times a month, and over $7 \%$ of customers did an online shopping every day. The results indicates that majority of respondents preferred to shop through social media with $70 \%$ of the respondents, while $47.6 \%$ of them chose to use online shopping application for their shopping and only $13.5 \%$ of respondents purchased online through websites. Moreover, the findings indicated that most respondents agreed that Facebook is the most preferred online shopping site for an organization to reach its target customers whereas almost 30\% of online shoppers chose Shopee to be their favorite app for online shopping. Specifically, Lazada and Instagram were covered by over $10 \%$ of online shoppers who agreed to rate them as the favorite shopping site, and only $4 \%$ of respondents mentioned other online shopping sites as their best shopping site such as Amazon.com, Taobao, Shein and Twitter. Lastly, the finding shows that $82.90 \%$ of the total respondents preferred to purchase clothes online. The following category was cosmetic that covers $48.20 \%$ of the total respondents, while $30 \%$ of the total respondents purchase online from the category "Books and Music" and "food and drink". In addition, few shoppers suggested other categories such as Baby \& Kids.

In conclusion, in order to effectively develop online business, the research reveals that focusing more on customer's privacy and security of personal information are important, and clearly providing product's description and shipping information also cannot miss out. Further, responses are commonly looking for a high resolution and clear product's images or videos. Design and appearance of the website, page and apps and multi payment options are also essential for online business to reach customers and influence online shopping behavior. Specially, few respondents have recommended that it is necessary for online business to offer an after-sale service, show product's review of other consumers, credibility and create a section for online shoppers to give feedback and comments.

\subsection{Discussion}

The findings of the study presented that all variables are statistically positive significant. The hypothesis testing in Table 3 showed the relationship and hypothesis between variables. Multiple and linear regression analysis was used to test the hypothesized relationship among the variables; all result measures with $\alpha=0.05$, F test $\mathrm{p}$ value (F test) $=0.000<\alpha$. Results showed that all variables were statistically significant. There was a significant relationship between digital marketing and online shopping applications in Thai Nguyen city since $t=12.288$ and $P=0.000<$ 0.05 . Thus, $\mathrm{H} 1$ was accepted. Furthermore, the relationship between online shopping application and online shopping behavior, as represented in regression output showed that $\mathrm{t}=12.862$ and $\mathrm{P}=$ $0.000<0.05$, so there was a significant relationship between these two variables and $\mathrm{H} 2$ was accepted. Finally, the relationship between digital marketing and online shopping behavior, as represented in regression output illustrated that $\mathrm{t}=8.941$ and $\mathrm{P}=0.000<0.05$, which indicated that there was a positive relation between digital marketing and consumer behavior in online shopping; therefore, H3 was supported. Finally, the finding concluded that online shopping application had the most impact on online shopping behavior due to the highest value regression coefficient $(\beta=0.534)$. That is determined to have a greater effect on online shopping behavior than digital marketing $(\beta=0.402)$. In fact, digital marketing also had a significant influence on online shopping applications with $\beta=0.515$. 


\section{Conclusion and recommendation}

\subsection{Conclusion}

The goal of this study is to investigate the impact of digital marketing on online shopping behavior toward online shopping applications with a specific focus on the retailer's industry. The study shows that digital marketing had a significant impact on online shopping behavior. As expected, online shopping applications partially mediated the relationship between digital marketing and online shopping behavior. Notably, digital marketing has become an essential marketing strategy for online retail's businesses that cannot miss and it is turning into the key strategy to benefit competitive advantages among the competitors, also to increase the profitability. The research showed that it is a great choice to use the right platforms of digital marketing and online channels to communicate with customers with a huge amount of information about the market consumer. The result shows that creating better content marketing of the online shopping sites is important for digital marketing. Hutchins et al. [18] proved that applying emotions in content marketing could trigger a competitive advantage and raise brand equity. Further, most responses prefer using the online shopping application that easily makes a purchasing process. As suggested by Zhang [19], "Online reviews have worked rather well as a part of their overall strategic business scheme." The study also found that the majority of customers agreed that reading products' reviews from other customers helped them before making a decision. The research showed that online shoppers mostly agreed that online shopping is difficult to judge the quality of products and they might get products that do not match what is described or expected. In addition, research finding recommended that it is necessary for online businesses to offer an after-sale service, show product's review of other consumers, credibility and create a section for online shoppers to give feedback and comments.

\subsection{Recommendation}

As with all studies, there are limitations to this research. Firstly, the scale used to measure the mediation of online shopping application influence on online shopping behavior in the retail industry based on only a few components. Therefore, instead of conducting it only by mediating with online shopping applications, future research could be conducted on other factors. Another interesting research area is the impact of digital marketing on online consumers' buying behavior. Secondly, this study was conducted within a limited duration, so a detailed and comprehensive study could not be made. Thirdly, the difficulty was found in translating the English questionnaire into Vietnamese version. Fourthly, a few respondents lacked know-how of using online devices to access and complete the survey that results in missing responses from selected shoppers. The next study should make it simple to access and answer the questions. Finally, as this experiment indicated only in one small city of Vietnam (Thai Nguyen), further research could be carried out to whole Vietnam as well as some other developing countries to provide broader insights on the impacts of digital marketing on online shopping behavior. It would be interesting and useful to compare the results and see the similarities and differences in the responses. This can be iconic as it can supply retailers with knowledge for their proper marketing tactics. Additionally, the findings and conclusions are based on knowledge and experience of the respondents and the study made by the investigator.

\section{REFERENCES}

[1] E. Abou-Elgheit, "Understanding Egypt's emerging social shoppers," Middle East Journal of Management, vol. 5, no. 3, pp. 207-270, 2018.

[2] M. Bala and D. Verma, "A Critical Review of Digital Marketing," International Journal of Management, IT \& Engineering, vol. 8, no. 10, pp. 321 - 339, 2018. [Online]. Available: 
https://www.academia.edu/37632966/A_Critical_Review_of_Digital_Marketing. [Accessed February 19, 2021].

[3] H. R. Gaber, L. T. Wright, and K. Kooli, "Consumer attitudes towards Instagram advertisements in Egypt: The role of the perceived advertising value and personalization," Cogent Business \& Management, vol. 6, no. 1, 2019, Art. no. 1618431.

[4] P. Kotler and G. Armstrong, Marketing: an introduction. Upper Saddle River, NJ: Pearson Prentice Hal, 2009.

[5] A. J. Parsons, M. Zeisser, and R. Waitman, Organizing for digital marketing, McKinsey Quarterly, 1996.

[6] G. R. Kiani, "Marketing opportunities in the digital world," Internet Research, vol. 8, no. 2, pp.185194, 1998.

[7] Y. B. Song, Proof That Online Advertising Works, Atlas Institute, Seattle, WA, Digital Marketing Insight, 2001.

[8] P. Kotler, H. Kartajaya, I. Setiawan, and Wiley InterScience (Online service), Marketing 3.0: From Products to Customers to the Human Spirit. New Jersey: John Wiley and Sons, 2010.

[9] P. Kotler, "Reinventing Marketing to Manage the Environmental Imperative," Journal of Marketing, vol. 75, pp. 132-135, 2011.

[10] W. Fan and M. D. Gordon, "the Power of Social Media Analytics," Communications of the ACM, vol. 57, no. 6, vol. 74- 81, 2014.

[11] P. S. Shukla, and P. V. Nigam, "E-shopping using mobile apps and the emerging consumer in the digital age of retail hyper personalization: An insight," Pacific Business Review International, vol. 10, no. 10, pp. 131-139, 2018.

[12] T. M. T. Hossain, S. Akter, U. Kattiyapornpong, and Y. K. Dwivedi, "Multichannel integration quality: A systematic review and agenda for future research," Journal of Retailing and Consumer Services, vol. 49, pp.154-163, 2019.

[13] T. M. T. Hossain, S. Akter, U. Kattiyapornpong, and Y. Dwivedi, "Reconceptualizing integration quality dynamics for omnichannel marketing," Industrial Marketing Management, vol. 87, pp. 225241, May 2020.

[14] A. Goswam, P. Baruah, and S. Borah, "Customer Satisfaction Towards Online Shopping with Special Reference to Teenage Group of Jorhat Town," Indian Journal of Research, vol. 3, no.4, pp. 239-241, 2013.

[15] A. Hardia and K. Sharma, "Empirical Study of Factors Affecting Online Shopping Amongst Youths," Global Journal of Management and Business Studies, vol. 3, no.2, pp. 91 - 96, 2013.

[16] S. Nazir, A. Tayyab, A. Sajid, H. Rashid, and I. Javed, "How Online Shopping Is Affecting Consumers Buying Behavior in Pakistan?" IJCSI International Journal of Computer Science Issues, vol. 9, issue 3, no. 1, pp. 486-494, 2012.

[17] W. Jonathan, Essentials of business research: a guide to doing your research project. SAGE Publication, 2010.

[18] J. Hutchins and D. X. Rodriguez, "The soft side of branding: Leveraging emotional intelligence," Journal of Business and Industrial Marketing, vol. 33, no. 1, pp. 117-125, 2018.

[19] G. Zhang, A. J. Dubinsky, and Y. Tan, "Impact of Blogs on Sales Revenue," International Journal of Virtual Communities and Social Networking, vol. 3, pp. 60-74, 2013. 